\title{
A pelagic thresher shark (Alopias pelagicus) gives birth at a cleaning station in the Philippines
}

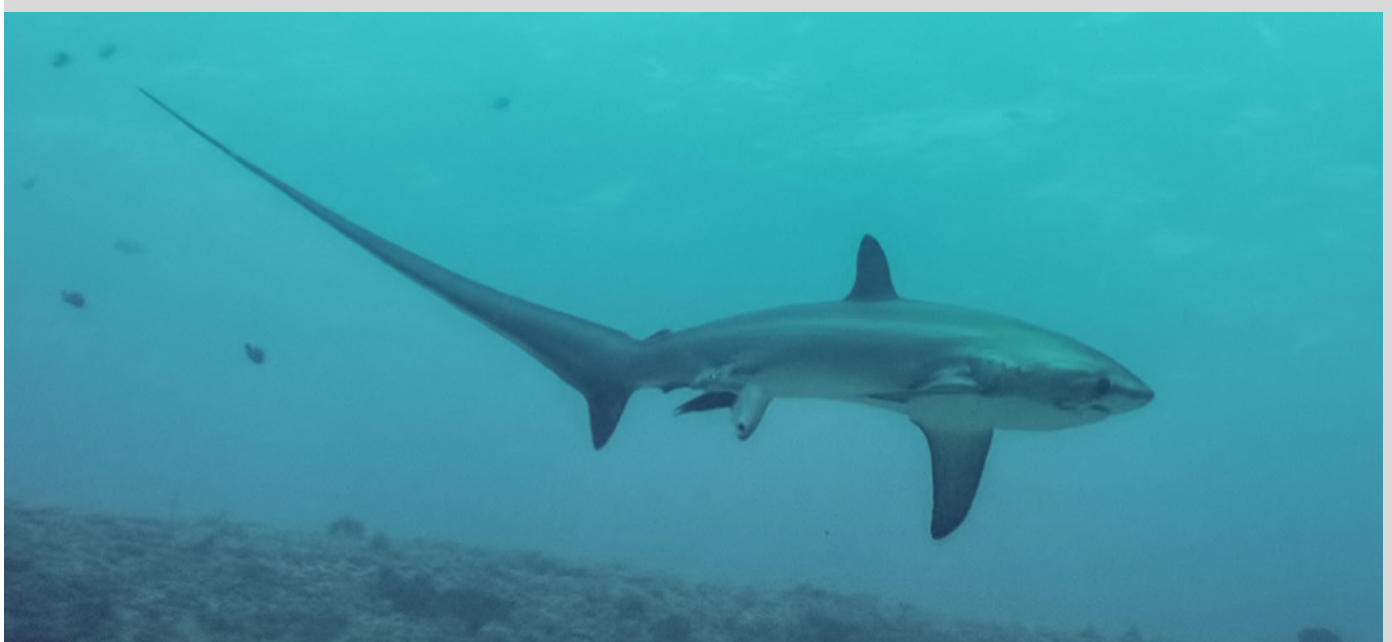

Fig. 1 A pelagic thresher shark gives birth at a cleaning station while a crescent wrasse bites at its cloaca

Parturient sharks have rarely been observed in the wild, and little is known of the reproductive strategies of most oceanic species. Here, we present photographic evidence that we captured on April 4, 2013, as the first record of a thresher shark giving birth.

At 0628 hrs, during a biological survey of Monad Shoal (N1 $1^{\circ} 19^{\prime} 06.7^{\prime \prime}$, E $\left.124^{\circ} 11^{\prime} 31.9^{\prime \prime}\right)$, we observed a large female pelagic thresher shark swimming back and forth across a cleaning station in an agitated state. We were unable to decipher the cause of the shark's distress from our observation post $15 \mathrm{~m}$ away, although it was evident that cleaner wrasse were taking bites from its pelvic region. We observed the shark for a total of 4 min, during which we took its photograph for identification purposes. The shark then left the cleaning station and was not observed again. Later, when we processed the photograph for analysis, it revealed the head of a pup emerging from the shark's cloaca (Fig. 1).

Pelagic thresher sharks have been described as having a cosmopolitan distribution with metapopulations occupying appropriate habitats across the globe (Tsai et al. 2010). Current evidence suggests that the gender and maturity dynamics of thresher sharks that visit Monad Shoal collectively comprise a single unit stock, which incorporates male, female, juvenile, transitional, and mature sharks, and includes gravid females (current data). While interactions among thresher sharks and cleaner fish are well documented at this site (Oliver et al. 2011), this is the first time cleaners have been seen interacting with a marine organism while it gives birth.

Acknowledgments We are grateful to Matthew Spencer, Howard Nelson, and Alison Beckett for providing helpful feedback.

\section{References}

Oliver SP, Hussey NE, Turner JR, Beckett AJ (2011) Oceanic sharks clean at coastal seamount. PLoS One 6:e14755

Oliver SP, Turner JR, Gann K, Silvosa M, D’Urban Jackson T (2013) Thresher sharks use tail-slaps as a hunting strategy. PLoS One 8:e67380

Tsai WP, Liu KM, Joung SJ (2010) Demographic analysis of the pelagic thresher shark Alopias pelagicus, in the north-western Pacific using a stochastic stage-based model. Mar Freshw Res 61:1056-1066

\section{S. P. Oliver $(\bowtie)$}

Department of Biological Sciences, University of Chester, Chester CH1 4BJ, UK

e-mail: s.p.oliver@threshersharkproject.org

S. P. Oliver · A. E. Bicskos Kaszo

The Thresher Shark Research and Conservation Project, Malapascua Island, Cebu, Philippines 